\title{
Leitura e autoria sob uma perspectiva dialógica na formação em Biblioteconomia no Brasil
}

\author{
Natália Raposo da Fonsêca \\ Mestre; Universidade Federal de Pernambuco, Recife, PE, Brasil; \\ nataliaraposof@gmail.com; ORCID: http://orcid.org/0000-0001-6996-6389 \\ Hélio Márcio Pajeú \\ Doutor; Universidade Federal de Pernambuco, Recife, PE, Brasil; \\ heliopajeu@gmail.com; ORCID: http://orcid.org/0000-0002-0657-1088
}

\begin{abstract}
Resumo: A leitura tem uma relação muito direta com a atuação do bibliotecário, ao mesmo tempo em que as discussões a seu respeito não ocupam lugar de destaque nos currículos de Biblioteconomia. O que se observa é um destaque para a leitura técnica, como a documentária. Nesse sentido, o objetivo desta pesquisa é verificar que lugar as questões de leitura e autoria ocupam nos cursos de Biblioteconomia no Brasil - tendo como recorte as regiões Norte e Nordeste - e sob quais perspectivas teóricas têm sido desenvolvidas na formação dos futuros bibliotecários. A partir de uma visão dialógica bakhtiniana, discute-se a leitura como um ato político, social, ideológico e responsável, entendendo o papel do bibliotecário como mediador de cultura e informação. $\mathrm{O}$ estudo se caracteriza como de natureza qualitativa, do tipo exploratório, descritivo e documentário. Analisa os projetos pedagógicos dos cursos de Biblioteconomia de 13 universidades federais do Norte e Nordeste, com foco nas disciplinas que tratam de leitura e autoria sob um viés dialógico. Destas, foram analisadas também ementas e, em alguns casos, as bibliografias. Os resultados mostram que a maioria dos cursos de Biblioteconomia analisados oferece alguma disciplina sobre leitura e autoria, entretanto ainda é uma oferta inexpressiva se comparada à quantidade de disciplinas "técnicas". Também se verificou uma tendência a pensar a leitura atrelada à literatura, ao livro, ao público infantojuvenil e à biblioteca escolar. Além disso, observou-se que o debate sobre autoria recebe pouco destaque, sendo diretamente mencionado em poucas ementas analisadas.
\end{abstract}

Palavras-chave: Leitura. Autoria. Biblioteconomia. Dialogismo.

\section{Introdução}

Quando falamos em leitura, a primeira imagem que vem à mente costuma ser a de um leitor, concentrado e silenciosamente, lendo e percorrendo com os dedos as páginas de um livro. Por considerarmos, então, que essa é uma boa prática, pensamos que todos devem ler muitos e variados livros (com predileção pela 
literatura) e que, em se tratando de estudantes, o hábito da leitura é essencial, sobretudo de clássicos e cânones da literatura nacional e internacional (ABREU, 2000). Quando falamos de estudantes de Biblioteconomia, essa associação torna-se ainda mais forte, uma vez que persiste no imaginário coletivo a imagem do bibliotecário sempre em meio a pilhas e prateleiras de livros.

De fato, a leitura permeia o cotidiano do bibliotecário, mas, apesar disso, não é uma temática que receba destaque nas matrizes curriculares dos cursos de graduação. A leitura "técnica", como a leitura documentária, por exemplo, costuma ser mais abordada, em detrimento de outras formas de leitura. Nesse sentido, a relevância desta pesquisa está em contribuir para que se lance um novo olhar sobre as questões de leitura e autoria no âmbito do ensino dos cursos de Biblioteconomia no Brasil.

Hoje, sabemos que o fazer bibliotecário não está restrito às atividades de classificação, catalogação e indexação de documentos. Logo, se o profissional não se restringe a organizar informação, também não deve ter uma formação limitada a isso. Ele deve ser capacitado para atuar numa perspectiva mais ampla e menos tecnicista, como um mediador de cultura e informação, entendendo a informação também como um objeto cultural e o mediador cultural como

[...] o articulador entre os bens culturais - saberes e objetos simbólicos - e um indivíduo, um grupo ou uma coletividade, por meio de dispositivos ou recursos instrumentais para acesso e apropriação desses bens. (LIMA; PERROTTI, 2016, p. 169).

Para tanto, é preciso entender a leitura para além do suporte livro, das obras canônicas e da figura mitificada do leitor. É preciso discutir e ensinar a leitura como um ato político, social, ideológico e responsável.

Nesse contexto, há de se considerar a importância de ampliar o entendimento a respeito da leitura e da autoria, num cenário onde a oferta de informações e de objetos culturais nas mais diversas plataformas é cada vez mais crescente. Entendemos que o bibliotecário tem um papel preponderante na desmistificação do discurso oficial sobre leitura: um discurso focado na relação direta do leitor com o livro e muito baseado no senso comum de que o brasileiro não lê (e, pior, não gosta de ler). No mesmo sentido, há de se entender também a 
autoria fora desse lugar sacro e mítico, pois todo enunciado, mesmo uma simples saudação, possui um autor e um destinatário (BAKHTIN, 2003); e pronunciar o mundo, modificá-lo (FREIRE, 1987), através da produção de textos, não deveria ser privilégio de poucos. Entretanto, para que o bibliotecário possa trabalhar para mudar essa realidade, é preciso, antes disso, que ele transforme sua própria visão, o que começa na sua formação acadêmica.

Partindo dessa perspectiva, o objetivo desta pesquisa é verificar que lugar as questões de leitura e autoria ocupam nos cursos de Biblioteconomia no Brasil — tendo como recorte as regiões Norte e Nordeste - e sob quais perspectivas teóricas têm se desenvolvido a formação dos futuros bibliotecários. Para isso, analisamos os projetos pedagógicos dos cursos de Biblioteconomia de 13 universidades federais do Norte e Nordeste, com foco nas disciplinas que tratam de leitura e autoria sob um viés dialógico. Dessas, foram analisadas também as ementas e, em determinados casos, as bibliografias. Os dados foram coletados, em sua maioria, dos sites das próprias instituições e, em alguns casos, de outras páginas da internet.

Assim, este artigo está dividido da seguinte forma: primeiro, discute a leitura para além do suporte livro, refletindo sobre os hábitos e tendências de leitura e a desmistificação do ato de ler e da figura do sujeito leitor. Em seguida, ainda na fundamentação teórica, a partir de uma visão dialógica bakhtiniana, discute a leitura como um ato político, social, ideológico e responsável, entendendo o papel do bibliotecário como mediador de cultura e informação. Por último, apresenta a metodologia, os dados organizados em gráficos e quadros e a discussão dos resultados encontrados, os quais indicam que a maioria dos cursos de Biblioteconomia analisados oferece alguma disciplina sobre leitura e autoria, entretanto, ainda é uma oferta inexpressiva se comparada à quantidade de disciplinas "técnicas". Outra constatação é uma tendência a pensar a leitura atrelada à literatura, ao livro, ao público infantojuvenil e à biblioteca escolar, além do pouco destaque dado para as questões de autoria. 


\section{A leitura além do livro}

O discurso oficial a respeito da leitura costuma estar cercado de mitos e de preconceitos. Ainda hoje, o senso comum propaga a ideia de que o brasileiro não lê e não gosta de ler, e que esse seria um dos motivos da nossa falta de letramento político. De fato, ler criticamente contribui sobremaneira para formar cidadãos mais conscientes de seu papel social, mas acreditamos que é preciso ter cuidado ao afirmar tão categoricamente que o brasileiro não lê.

$\mathrm{Na}$ contramão desse pensamento, vemos a proliferação de canais e perfis literários no Youtube e no Instagram, respectivamente; a criação de clubes de leitura, além das frequentes adaptações de livros para o cinema, o que também impulsiona a leitura e a venda dos títulos. Entre feeds e timelines de redes sociais, o brasileiro é capaz de ler bem mais do que as pesquisas atestam ao levar em consideração somente a quantidade de livros lidos, por pessoa, ao ano. É preciso discutir o que se considera leitura e quem é considerado leitor.

Para Augusto Assis, professor de Literatura e um dos idealizadores do canal Vá ler um livro, em parceria com a também professora Tatiany Leite, o conceito de leitura deve ser ampliado para contemplar todas as possibilidades que se tem hoje e que não se tinha no tempo em que a leitura necessariamente era a de impressos, sobretudo livros. Ele afirma que várias coisas podem ser consideradas leitura e que é preciso ampliar o horizonte, enxergando novos gêneros literários — tais como textos de blog, fanfic, "thread" do Twitter também como textos importantes (VÁ LER UM LIVRO, 2019).

De acordo com os dados da $4^{\text {a }}$ edição da pesquisa Retratos da Leitura no Brasil, de 2015, desenvolvida pelo Instituto Pró-Livro, o brasileiro lê, em média, 2,43 livros por ano, índice muito baixo, mas que leva em consideração somente a leitura de livros. Vale ressaltar a definição de leitor/não leitor utilizada pela pesquisa e que se mantém inalterada desde 2007: leitor seria todo aquele que leu, inteiro ou em partes, pelo menos um livro nos últimos três meses; e não leitor, todo aquele que declara não ter lido nenhum livro nos últimos três meses, mesmo que tenha lido no período de um ano (FAILLA, 2016). 
Por sua vez, Ceccantini (2016, p. 83) centra-se nos dados revelados em relação à leitura dos jovens, dados que

[...] vão na contramão dessa visão apocalíptica, reiterando um cenário bem mais alentador sobre o perfil dos jovens como leitores do que o usualmente apontado, sobretudo se for considerado o contexto da população brasileira como um todo.

Ele destaca, ainda, que diversas pesquisas e projetos desenvolvidos nas duas últimas décadas vêm apontando para essa tendência otimista sobre a leitura entre os mais jovens.

Dessa forma, tanto a leitura e o leitor (e aqui cabe incluir, também, o autor) quanto o olhar que se tem sobre eles dependem do contexto do qual parte o observador, de suas intenções e dos discursos com os quais dialoga. Falar de leitura e do ato de ler pressupõe que haja um autor, um texto (não necessariamente escrito, mas um objeto a ser lido) e um leitor. Pressupõe contexto, elementos externos ao texto, essenciais para a constituição de sentidos.

Britto e Barzotto (1998) destacam o mito do sujeito leitor e explicam que essa mitologia cria e se apoia num tipo de discurso que desconsidera os diferentes contextos dos indivíduos enquanto leitores, ignorando como os sujeitos estão inseridos nas formas de cultura. Ademais, ainda estabelece juízos de valor em torno da leitura, reduzindo a questão ao maniqueísmo bom e mau, além de não se apoiar em estudos objetivos e confiáveis sobre práticas de leitura. O mito do sujeito leitor, sintetizado em diversos ditados populares, contestados pelos autores, tem, assim, forte apelo no e para o senso comum.

É importante considerar o contexto sociocultural e histórico que alicerça as referências do leitor, levando-o a interpretar o texto de uma maneira, e não de outra. A interpretação do leitor não surge do nada, assim como a intenção do autor também tem um porquê. Desse modo, o encontro do leitor com o texto não é asséptico, despido de ideologias, de intencionalidades, de referências; a “interpretação do leitor”, portanto, não é só sua, é dele e de tudo o que o antecedeu, possibilitando que interpretasse algum texto. 
Para que o bibliotecário, no seu fazer profissional, consiga atuar como mediador de informação e cultura a partir desse norte, é preciso que lhe seja dada a oportunidade de refletir sobre essas questões desde a graduação. Por isso, é importante que disciplinas que enfoquem a leitura sob um viés mais amplo, como o proposto por esta pesquisa, constem nas matrizes curriculares dos cursos de Biblioteconomia. Trata-se de uma discussão para a qual intentamos contribuir, incentivando docentes e discentes a pensar formas de ensinar e de aprender leitura e autoria sob o viés dialógico, com vista à formação bibliotecária.

\section{A leitura e a autoria como atos dialógicos}

Há uma relação simbiótica entre autor, texto e leitor, mas ela só se concretiza quando consideramos "[...] as relações dialógicas que constituem os processos de leitura e de autoria. Neste sentido, a autoria é constituinte e organizadora do objeto estético, posto que seja a consciência que lhe dá forma a partir de textos" (PAJEÚ, 2016, p. 12). Ou seja, os discursos do sujeito, quando tomados como objeto de estudo, só podem ser considerados como partes de teias dialógicas.

Ao tratar das questões de autoria, o Círculo de Bakhtin insiste na constituição mútua das esferas ética e estética, em que a ética refere-se ao processo, ao agir no mundo, à necessidade de ocupar o lugar singular e único na vida concreta que se liga diretamente à realidade, de empreender atos responsáveis inacabados, isto é, a ética na concepção bakhtiniana corresponde ao espaço de tomada de decisões cronotópicas no aqui e agora concretos do agir humano, como um conjunto de obrigações e deveres dos sujeitos.

Para Geraldi (2010, p. 111),

[...] no mundo dos acontecimentos da vida, campo próprio do ato ético, estamos sempre inacabados, porque definimos o presente como consequiência de um passado que construiu o pré-dado e pela memória do futuro com que se definem as escolhas no horizonte das possibilidades. Nosso acabamento atende a uma necessidade estética de totalidade, e esta somente nos é dada pelo outro, como criação e não como solução. A vida, concebida como acontecimento ético aberto, não comporta acabamento e, portanto, solução. 
A partir do pensamento do professor Geraldi (2010), fundamentado nos estudos bakhtinianos, apreendemos que os sujeitos são incompletos por natureza, o que é inerente às interações traçadas no campo da ética. Porém, é na esfera estética que se dá o acabamento provisório dos enunciados.

A estética, por sua vez, aparece como a esfera que arquiteta os modos de agir dos sujeitos. O objeto estético encarna uma valoração, uma reflexão elaborada, portadora de acabamento - mas não essencialmente fechada, completa — acerca da ação ética desempenhada pelo sujeito a partir da linguagem. A concepção estética resulta de um processo que busca representar o mundo sob um ponto de vista exotópico do sujeito, de um posicionamento de fronteira do qual os sujeitos enxergam o mundo com adequado distanciamento; para transfigurá-lo na edificação da sua palavra estética e que carrega também os aspectos sociais e históricos, isto é, a estética se trata do lugar da representação, da transfiguração, do simulacro do ato ético.

A memória colocada nos entremeios da vida não funciona como um excedente de visão do todo acabado dos sujeitos, uma vez que, de acordo com Geraldi (2010, p. 107), na “[...] vida não há um autor e, se estou vivendo, tenho um por-vir e, portanto, sou inacabado", mas, ao atravessar o processo de transgenerização dos enunciados, da ética à estética, é aí que o autor constrói um excedente de visão dos acontecimentos da vida.

Na Estética da Criação Verbal, Bakhtin (2003, p. 10), ao tratar da relação do autor e do herói, considera autor como sendo "[...] o agente da unidade tensamente ativa do todo acabado, do todo do personagem e do todo da obra, e este é transgrediente a cada elemento particular desta". É ele a consciência, das consciências, que junta e conhece as ideias, os acontecimentos, os personagens e seus mundos, sabendo sua arquitetônica, algo que é inacessível a eles próprios. Na criação estética, de acordo com Clark e Holquist (1998), podemos ainda considerar o autor, no viés bakhtiniano, como aquele que transcreve o que está na vida, refletindo isso por meio de obras de arte, de textos, de gêneros do discurso secundários.

Deste modo, 
[...] se todo sujeito é criador potencial de texto, a noção de autor se amplia a todos os sujeitos como arquitetos da discursividade social. É a autoria, então, que dá ao enunciado seu caráter de acontecimento histórico decisivo. (ARÁN, 2014, p. 9).

Para o Círculo de Bakhtin, é o processo de constituição do autor que aproxima as esferas ética e estética, visto que se compreende a autoria sob duas perspectivas: o autor criador e o autor pessoa.

Faraco (2009), a partir do pensamento bakhtiniano, compreende que o autor-criador é distinto do autor-pessoa ainda que um se alimente do outro e não viva sem ele. Como criador, o autor tem emprego estético-formal que concebe a obra e concretiza a relação valorativa descoberta do interior de suas criações e os traços recorrentes, característicos de suas obras, apontam a sua assinatura autoral, o que se pode nomear de estilo autoral. Já o autor pessoa se trata do sujeito que vive o ato concreto no existir da vida.

Destarte, nessa perspectiva,

[...] ser autor é assumir, de modo permanentemente negociado, posições que implicam diferentes modalidades de organização dos textos, a partir da relação com o herói e com o ouvinte. A própria seleção de palavras envolve uma orientação na direção do ouvinte e do herói autor e a recepção a essa seleção advêm do contexto da vida, que impregna as palavras de juízos de valor, impondo, pois, ao seu significado uma direção específica, podendo mesmo pensar na recepção como uma espécie de co-seleção lexical. (SOBRAL, 2012, p. 143).

Para o Círculo de Bakhtin, portanto, o autor é aquele que dá um acabamento provisório aos acontecimentos éticos na esfera estética, isto é, o autor criador é aquele que estrutura o discurso, oral ou escrito, a partir de um acabamento provisório e possibilita interações com outros sujeitos, leitores, por meio de gêneros do discurso e textos variados. Nessa esteira de pensamento, a formação do bibliotecário está mediada pelo processo de autoria, ainda que não seja explicitada, tampouco trabalhada de forma singular nas disciplinas que compõem sua formação, como veremos mais adiante, uma vez que ele, em todo seu fazer, cria, recria, estrutura discursos, dando sempre um acabamento, ainda que provisório, aos textos que produz, sejam literários ou acadêmicos. 
O texto, nessa perspectiva, ganha vida quando em contato com outros textos, e só tem sentido dentro de um contexto. Isso porque os sentidos se modificam quando também o fazem os contextos. Sobre esse diálogo entre enunciados, Bakhtin (2003) explica:

O texto só vive em contato com outro texto (contexto). Somente em seu ponto de contato é que surge a luz que aclara para trás e para frente, fazendo que o texto participe de um diálogo. Salientamos que se trata do contato dialógico entre os textos (entre os enunciados), e não do contato mecânico "opositivo", possível apenas dentro das fronteiras de um texto (e não entre texto e contextos), entre os elementos abstratos desse texto (entre os signos dentro do texto), e que é indispensável somente para uma primeira etapa da compreensão (compreensão da significação e não do sentido). Por trás desse contato, há o contato de pessoas e não de coisas. Assim que convertermos o diálogo num texto compacto, ou seja, assim que apagarmos a distinção das vozes (a alternância dos sujeitos falantes) - o que é em princípio possível (a dialética monológica de Hegel) - o sentido profundo (infinito) desaparecerá (teremos batido no fundo, ficaremos em ponto morto). (BAKHTIN, 2003, p. 405-406).

Tanto os discursos quanto os sujeitos são, portanto, constituídos a partir das relações dialógicas que se apresentam na construção da linguagem. Bakhtin (2011, p. 153) pontua que uma obra artística, tomada fora de uma situação comunicativa, representa somente um objeto, “[...] se faz artística somente no processo de interação do criador com o ouvinte como situação essencial no acontecimento desta interação". O teórico russo acrescenta, ainda, que tudo aquilo que, numa obra de arte, estiver fora desse processo criador/ouvinte, não poderá ter significado artístico.

Da mesma forma, Freire (1989) considera que a leitura acrítica, que se restringe à mera decodificação de signos linguísticos, perdendo de vista o caráter político do ato de ler, sequer pode ser chamada de leitura. Na perspectiva freiriana, a interação entre os sujeitos (aquele que lê, aquele que escreve e todos os outros que produziram/produzem discursos que atravessam o texto lido) dá-se no encontro dialogado entre esses sujeitos, o que só é possível quando há um leitor que, entendendo essa dimensão, questiona, discute com aquilo que lê. "Entrar na corrente do diálogo é renunciar à fala monológica, que seduz o outro de modo autoritário e impede a manifestação do caráter dialógico" (SOUZA, 2005, p. 319). 
Se Bakhtin considera as interações e relações humanas como nascedouro dos discursos, das ideologias e dos embates sociais, conforme pontua Pajeú (2014), podemos então pensar na atividade bibliotecária como seu leito, por onde correm discursos e ideologias. Como elo entre a informação e o usuário, o bibliotecário atravessa e é atravessado pelos discursos tanto dos autores quanto dos leitores. Se pensarmos que mesmo as atividades técnicas de classificação, catalogação e indexação precisam necessariamente ser realizadas pressupondo um outro - o usuário —, e que o diálogo do bibliotecário não se dá somente com o usuário previsto, mas também com os autores de cada documento, cada material que lhe passa pelas mãos, então podemos dizer que as práticas bibliotecárias são em si práticas dialógicas (ou, pelo menos, deveriam ser).

Tanto Bakhtin quanto Freire sublinham a não neutralidade do texto, estruturado a partir de signos ideológicos. O corpo/objeto físico, por si só, não constitui um produto ideológico; ele coincide inteiramente com sua própria natureza. Assim, um objeto de leitura, tomado como corpo físico, descolado de um contexto, é apenas um objeto, não se trata de ideologia. Entretanto, esse mesmo corpo pode ser percebido como símbolo, pois, conforme explica Bakhtin (2006, p. 29),

[...] toda imagem artístico-simbólica ocasionada por um objeto físico particular já é um produto ideológico. Converte-se, assim, em signo o objeto físico, o qual, sem deixar de fazer parte da realidade material, passa a refletir e a refratar, numa certa medida, uma outra realidade.

Dito de outra forma, Bakhtin ressalta que tudo que é ideológico tem um significado e remete a algo que lhe é exterior, reflete e refrata realidades exteriores. Nesse sentido, a compreensão de um signo se dá pelo encontro, pela comparação dele com outros signos já conhecidos, o que nos remete ao processo de alfabetização e pós-alfabetização, logo, leitura e escrita, defendido por Paulo Freire, segundo o qual o alfabetizando deve aprender essas duas práticas não mecanicamente, mas no contexto de signos que lhe sejam familiares.

Miotello (2012, p. 171) acrescenta que, para Bakhtin, a subjetividade dos indivíduos se constitui nas ações discursivas e nas atividades humanas que "[...] oferecem espaços de encontros de constituição da subjetividade, pela 
constituição de sentidos", espaços que representam outra posição ante a dicotomia ideologia dominante/ideologia dominada, os lugares de negociação.

Acreditamos que as bibliotecas, em alguma medida, funcionem como esses locais e, nesse sentido, o bibliotecário, como incentivador da leitura, tem um papel importante. Contudo, para que ele de fato possa desempenhar esse papel, é necessário que a formação universitária lhe forneça subsídios teóricos para tal (a exemplo das disciplinas de leitura numa perspectiva não só documental), levando-o a ter consciência das potencialidades e da importância desse outro lado da profissão, um lado que pode contribuir sobremaneira para a formação de cidadãos mais críticos, conscientes e atuantes na sociedade.

Assim, buscamos dialogar com Mikhail Bakhtin, cuja perspectiva dialógica estrutura a concepção de leitura que defendemos. O conceito de dialogismo é central em sua obra, pois todo discurso é atravessado por uma série de outros discursos (FONSÊCA; GOMES, 2014), conforme explica o autor:

A orientação dialógica é naturalmente um fenômeno próprio a todo discurso. Trata-se da orientação natural de qualquer discurso vivo. Em todos os seus caminhos até o objeto, em todas as direções, o discurso se encontra com o discurso de outrem e não pode deixar de participar, com ele, de uma interpretação viva e tensa. (BAKHTIN, 1988, p. 88).

Fonsêca e Gomes (2014) comentam a dinâmica das vozes, que, nas relações dialógicas, se dá tanto no âmbito individual quanto no social, alternando-se a predominância de um desses dois aspectos de acordo com as situações enunciativas em que essas vozes se encontram.

Um discurso pode ser o lugar onde se encontram vozes individuais [...], ou sociais [...]. Entretanto, é importante pensarmos que os conceitos de social e individual em Bakhtin não são estanques, nem tão simplórios como no binômio indivíduo/sociedade. (FONSÊCA; GOMES, 2014, p. 4).

Apesar de considerar que a maioria dos enunciados individuais é social, o sujeito do discurso, para Bakhtin, não é assujeitado, não é desprovido de sua subjetividade em favor do social. Cada indivíduo é social e individual. Se considerarmos o paradigma construtivista, teremos que os indivíduos tanto contribuem para a construção social da realidade quanto são constituídos por 
essa mesma realidade — num movimento incessante e dialético - ${ }_{-}$logo, os discursos se constroem, individual e socialmente, num movimento similar.

O primeiro conceito de dialogismo diz respeito, pois, ao modo de funcionamento real da linguagem: todos os enunciados constituem-se a partir de outros. Nesse sentido, pensar a mediação de leitura considerando a palavra como neutra, objetiva e descontextualizada, tal como os processos de organização da informação têm feito em muitos de seus estudos, não é positivo para a formação de leitores, porque desconsidera o papel central da dialogicidade.

Ao falar sobre a importância da leitura, Paulo Freire (1989, p. 13) frisa que a leitura da palavra é sempre precedida da leitura do mundo, numa relação dialética e indissociável.

Podemos ir mais longe e dizer que a leitura da palavra não é apenas precedida pela leitura do mundo, mas por uma certa forma de "escrevê-lo" ou de "reescrevê-lo", quer dizer, de transformá-lo através de nossa prática consciente.

A leitura, portanto, não se restringe à decodificação de signos linguísticos. Também implica decodificar as inter-relações entre o texto e o contexto subjacente. "Toda palavra (todo signo) de um texto conduz para fora dos limites desse texto. A compreensão é o cotejo de um texto com os outros textos. O comentário. Dialogicidade deste cotejo" (BAKHTIN, 2003, p. 405).

No texto A importância do ato de ler, Paulo Freire descreve seu próprio processo de alfabetização, que se deu com palavras do seu mundo de criança, e não do mundo maior de seus pais. Segue narrando que anos depois, já como professor de Português, experimentou intensamente o elo entre os atos de ler e de escrever, propondo a seus alunos um aprendizado dinâmico de temas tão cheios de regras, como regência verbal, concordância e crase: "[...] nada disso era reduzido por mim a tabletes de conhecimentos que devessem ser engolidos pelos estudantes" (FREIRE, 1989, p. 9).

Leitura e memorização mecânicas da palavra não levam o estudante, o leitor-autor, de modo geral, a produzir conhecimento. A leitura de um texto que somente descreve objetos e situações descolados do contexto do sujeito, feita para memorizá-la, segundo Freire (1989), sequer é leitura real, tampouco resulta em algum conhecimento acerca do que o tex to trata. 
Ao falar sobre a alfabetização de adultos, Paulo Freire (1989, p. 13) explica que as palavras utilizadas nos programas de alfabetização deveriam vir do "universo vocabular" dos alfabetizandos, e não do universo do educador.

Deveriam vir carregadas da significação de sua experiência existencial e não da experiência do educador. A pesquisa do que chamava universo vocabular nos dava assim as palavras do Povo, grávidas de mundo. (FREIRE, 1989, p. 13, grifo nosso).

Nessa perspectiva, podemos pensar no bibliotecário e no leitor, este muitas vezes já alfabetizado, mas ainda não capaz de ler criticamente um texto, relacionando-o com suas prévias leituras do mundo.

No que tange às questões de leitura, o bibliotecário precisa reconhecer os mundos gestados nas palavras do povo, para assim ser capaz de estimular os hábitos de leitura e atender às necessidades informacionais que, por vezes, o usuário sequer sabe que tem.

[...] não bastam conhecimentos técnicos da área de biblioteconomia, educação e leitura. Ele [o bibliotecário] precisa se envolver com sua comunidade, saber e gostar de trabalhar com crianças, adolescentes e adultos. (ALMEIDA JUNIOR; BICHERI, 2013, p. 44).

É comum que o usuário, muitas vezes, identifique erroneamente suas lacunas informacionais ou mesmo nem consiga identificá-las; e o bibliotecário, se bem preparado, é capaz de efetivamente auxiliá-lo nesse processo.

Como agente de cultura e educação, o bibliotecário deve ter em mente que não se pode pensar a educação sem estar atento à questão do poder. Contudo, pontua Freire (1989), o fato de o educador não ser neutro não implica que sua prática seja manipuladora. Educar (e informar) para a libertação dá-se por meio de práticas não manipuladoras, tampouco ingênuas. O bibliotecário, nesse sentido, deve estar ciente do potencial transformador de sua profissão.

$\mathrm{O}$ autor critica aqueles que insistem em elitizar o ato de ler, colocando-o como elemento de distinção social, e pontua que, contra esse pensamento, se coloca a biblioteca popular em sua posição crítico-democrática.

Como centro cultural e não como um depósito silencioso de livros, [a biblioteca popular] é vista como fator fundamental para o aperfeiçoamento e a intensificação de uma forma correta de ler o texto em relação com o contexto. (FREIRE, 1989, p. 20). 
Disso decorre a necessidade de que a biblioteca estimule a formação de leitores e de grupos de leitura onde se travem discussões críticas que permitam ao leitor se aprofundar nos textos, além de vivenciar experiências estéticas próprias da linguagem popular.

Sousa e Feitoza (2018, p. 58) estudaram como a leitura, a partir do ponto de vista da responsabilidade social, é tratada nos cursos de Biblioteconomia, pensando a formação do bibliotecário como mediador literário. Elas concluíram que "[...] a formação do bibliotecário ainda é pouco voltada para capacitar profissionais para interagir com as ações de mediação de leitura, formação e promoção de leitura no âmbito social".

As autoras definem o mediador de leitura como aquele que

[...] medeia, intervém, aproxima o leitor do texto. Em outras palavras, o promotor da relação <leitor - objeto - leitura>. Mas também aquele que pode despertar no sujeito o interesse e a curiosidade pelo mundo das leituras, especialmente a literária. (SOUSA; FEITOZA, 2018, p. 63) .

Para isso, o mediador utiliza diversos artifícios para chamar a atenção do leitor, não se restringindo à contação de história, muitas vezes, erroneamente, entendida como sinônimo de mediação de leitura.

Pontuam, ainda, que o bibliotecário tem múltiplos papéis na sociedade e que, por isso, deve desenvolver habilidades de ordens diversas, que o capacitem a desempenhar funções que vão desde as mais técnicas até as mais sociais e lúdicas. Alguns tipos de bibliotecas, como as públicas e as escolares, precisam especialmente de um bibliotecário que tenha "[...] perfil de educador, leitor e principalmente mediador social, quando se utiliza de artifícios para aproximar o leitor do texto literário" (SOUSA; FEITOZA, 2018, p. 60).

Por sua vez, Pajeú e Almeida (2020, p. 12), destacam que o bibliotecário não deve "[...] ficar preso à prática da técnica ou ações unicamente voltadas ao incentivo à leitura, ainda que ambas sejam de extrema importância, pois este deve ser um mediador entre os usuários e os instrumentos informacionais". E acrescentam que a mediação do bibliotecário possibilita ao usuário acessar instrumentos que contribuam para sua formação como cidadão. 


\section{Metodologia e discussão dos resultados}

Esta pesquisa tem abordagem qualitativa e se caracteriza, quanto aos fins, como uma pesquisa exploratória e descritiva; e quanto aos meios, como documentária (VERGARA, 2003). Exploratória porque é uma pesquisa que se dedica à descoberta e à elucidação de fenômenos - no caso, verificar se de fato a leitura de uma perspectiva dialógica é relegada a segundo plano nos cursos de Biblioteconomia no Brasil, e descritiva na medida em que descreve as ementas das disciplinas selecionadas dos Projetos Pedagógicos dos Cursos (PPCs) com a mínima interferência do pesquisador. Já a pesquisa documentária tem como característica o fato de ter documentos como fonte de coleta, ou seja, fontes primárias (no nosso caso, os PPCs).

No percurso metodológico, iniciamos com o levantamento bibliográfico que fundamenta a pesquisa; em seguida coletamos os Projetos Pedagógicos dos Cursos de Biblioteconomia das universidades, localizados nos sites das respectivas instituições e em outros sítios na internet. Realizamos uma análise documental dos PPCs, identificando as disciplinas sobre leitura e autoria que interessam para esta pesquisa, analisando suas ementas e, também, suas bibliografias, quando disponíveis. Organizamos essas informações em quadros e gráficos que discutimos nos resultados aqui apresentados.

A pesquisa analisou os Projetos Pedagógicos dos cursos de Biblioteconomia $^{1}$ de 11 das 13 Instituições Federais ${ }^{2}$ de Ensino Superior (IFES) das regiões Norte e Nordeste. Os únicos estados onde nenhuma instituição pública de ensino superior oferece o curso são Amapá, Roraima e Acre, todos da região Norte. Dessa forma, as instituições selecionadas para análise nesta pesquisa foram: Universidade Federal de Alagoas (UFAL), Universidade Federal do Amazonas (UFAM), Universidade Federal da Bahia (UFBA), Universidade Federal do Ceará (UFC), Universidade Federal do Cariri (UFCA), Universidade Federal do Maranhão (UFMA), Universidade Federal do Pará (UFPA), Universidade Federal da Paraíba (UFPB), Universidade Federal de Pernambuco (UFPE), Universidade Estadual do Piauí (UESPI), Universidade 
Federal do Rio Grande do Norte (UFRN), Fundação Universidade Federal de Rondônia (UNIR) e Universidade Federal de Sergipe (UFS).

Pontuamos que, em 2018, foi aprovado pelo Ministério da Educação o curso de Biblioteconomia na modalidade a distância em 11 universidades federais. Cinco destas estão entre as instituições que compõem nosso corpus de análise: UFAM, UFBA, UFPA, UFPB e UFS. Os cursos das Federais da Bahia e de Sergipe já estão em funcionamento, entretanto não os incluímos nesta pesquisa. Apesar disso, buscamos as matrizes curriculares de ambos (a do curso da UFBA não foi localizada) e observamos que o currículo do curso a distância $(E a D)$ da UFS difere do currículo do curso presencial, inclusive em relação às disciplinas relacionadas à leitura, objeto deste estudo.

No Quadro 1, abaixo, elencamos as universidades selecionadas para a pesquisa e indicamos em quais delas são encontradas, nos cursos de Biblioteconomia, disciplinas que tratam das questões de leitura e autoria numa perspectiva dialógica, de constituição da subjetividade dos indivíduos para a formação crítica. Também indicamos a quantidade de disciplinas encontradas, bem como se elas são obrigatórias ou optativas.

Os PPCs foram coletados em sua maioria nos sites das instituições. Alguns deles não foram encontrados diretamente nesses locais, e sim em pesquisa mais detalhada na internet. Já os PPCs dos cursos da UFBA, UESPI e UFS não foram localizados de nenhuma forma, de modo que tivemos acesso somente às matrizes curriculares e, em dois casos, também às ementas de cada componente curricular, permitindo-nos, assim, verificar se havia as disciplinas que nos interessavam. Por tal razão, essas três universidades aparecem assinaladas com asterisco no Quadro 1, abaixo.

Quadro 1 - Relação da ocorrência de disciplinas sobre leitura e autoria nos cursos de Biblioteconomia das IFES das regiões Norte e Nordeste.

\begin{tabular}{|c|c|c|c|c|c|}
\hline \multirow[t]{2}{*}{ UF } & \multirow[t]{2}{*}{ IFES } & \multirow[t]{2}{*}{$\begin{array}{c}\text { DISCIPLINA } \\
\text { SOBRE } \\
\text { LEITURA }\end{array}$} & \multirow[t]{2}{*}{ QTD. } & \multicolumn{2}{|c|}{$\begin{array}{c}\text { TIPO DA } \\
\text { DISCIPLINA } \\
\text { (Obrigatória ou } \\
\text { optativa) }\end{array}$} \\
\hline & & & & OB & OP \\
\hline $\mathbf{A L}$ & UFA & $X$ & 2 & & X \\
\hline $\mathbf{A M}$ & UFAI & X & 1 & & X \\
\hline
\end{tabular}




\begin{tabular}{|c|c|c|c|c|c|}
\hline BA & UFBA* & & & & \\
\hline \multirow{2}{*}{ CE } & UFC & X & 1 & $X$ & \\
\hline & UFCA & X & 1 & X & \\
\hline MA & UFMA & X & 1 & X & \\
\hline PA & UFPA & X & 1 & X & \\
\hline PB & UFPB & X & 1 & X & \\
\hline PE & UFPE & X & 1 & & X \\
\hline PI & UESPI* & X & 1 & X & \\
\hline RN & UFRN & $\mathrm{X}$ & 2 & $\mathrm{X}$ & $\mathrm{X}$ \\
\hline RO & UNIR & $X$ & 1 & X & \\
\hline SE & UFS* & $X$ & 1 & $X$ & \\
\hline
\end{tabular}

Fonte: Dados da pesquisa (2019).

No caso da UFBA, a partir da matriz curricular e das ementas, o que observamos é que o curso de Biblioteconomia não oferece disciplina sobre leitura, sendo, portanto, a única universidade estudada onde isso ocorre. Já em relação à UESPI, não tivemos acesso nem às ementas das disciplinas. O curso não tem site, nem disponibiliza esses documentos em qualquer outro local. A única informação localizada foi a matriz curricular dos cursos, disponível no site da universidade, em que pudemos ver que existe a disciplina Leitura e formação de leitores, obrigatória, com carga-horária de 60h. Acreditamos que ela atenda aos nossos propósitos, por isso a incluímos no Quadro 1, mas pontuamos a necessidade da ementa para melhor análise.

Quanto à UFS, não acessamos o PPC, mas localizamos a Resolução nº 95/2011, do Conselho do Ensino, da Pesquisa e da Extensão, que aprova alteração no Projeto Pedagógico do curso de Biblioteconomia e Documentação da universidade e dá outras providências. Neste documento, embora não conste o PPC na íntegra, encontra-se a estrutura curricular e o ementário das disciplinas. Além disso, tivemos acesso à matriz curricular disponível no Sistema Integrado de Gestão de Atividades Acadêmicas (Sigaa), onde também se encontram os programas das disciplinas.

A partir de 2018, a UFS passou a oferecer o curso de Biblioteconomia na modalidade a distância, e o currículo do curso EaD diverge do currículo do presencial. Na modalidade $\mathrm{EaD}$, existe a disciplina obrigatória Leitura e ação cultural, que não há no curso presencial; além desta, outra exclusiva do curso a distância é a optativa Leitura e literatura infantil e juvenil. 
Das 13 universidades selecionadas, o curso de Biblioteconomia de 12 delas oferece disciplina sobre a temática de leitura. Desses 12, a maioria (dez) oferece somente uma disciplina; apenas a UFAL e a UFRN oferecem duas, sendo que a primeira oferta duas obrigatórias e a segunda, uma obrigatória e uma optativa. Ainda em relação ao tipo de disciplina ofertada, conforme o Gráfico 1, abaixo, percebe-se uma maior ocorrência de obrigatórias (64\%), contra $36 \%$ de optativas. Desses dados, podemos inferir que, embora a formação de bibliotecários como mediadores de leitura (e por que não de autoria?) numa perspectiva dialógica, não pareça estar no centro da preocupação dos cursos de Biblioteconomia, pelo menos o fato de a maioria das poucas disciplinas ofertadas serem obrigatórias garante que os estudantes não saiam do curso sem o mínimo contato com discussões caras à atuação do bibliotecário nesse sentido.

Bortolin (2010, p. 116) afirma: "[...] sendo a biblioteca uma agência mediadora, o bibliotecário não pode se esquivar da mediação da leitura, visto que o ato de ler precede o ato de se informar, descobrir e investigar". Por isso, mediar a leitura é tão importante e fundamental quanto disponibilizar documentos aos usuários, ou seja, mediar a informação.

Gráfico 1 - Tipos de disciplinas sobre leitura e autoria nos cursos de Biblioteconomia das IFES do Norte e Nordeste.

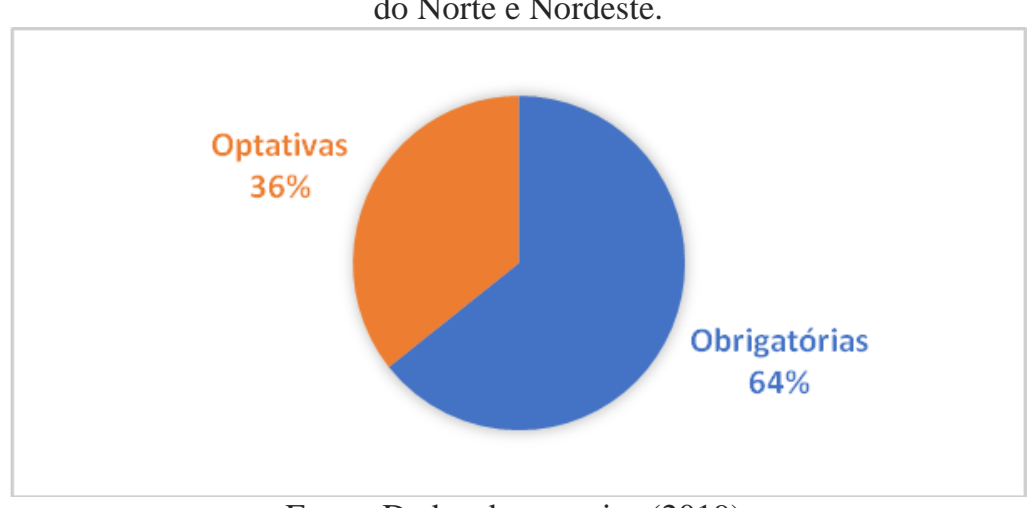

Fonte: Dados da pesquisa (2019).

Já o Gráfico 2 mostra a distribuição, por universidade, dos tipos de disciplinas, obrigatórias e optativas, em relação aos componentes curriculares que tratam da temática de leitura. Dos estados do Norte (UFAM, UFPA e 
UNIR), somente a UFAM oferece optativa; as outras três instituições onde isso ocorre são do Nordeste (UFAL, UFPE e UFRN), o que se justifica também pela quantidade de estados dessa região, sendo que em todos eles há o curso de Biblioteconomia. O gráfico ressalta a prevalência de disciplinas obrigatórias.

Gráfico 2- Disciplinas de leitura e autoria dos cursos de Biblioteconomia das IFES do Norte e Nordeste.

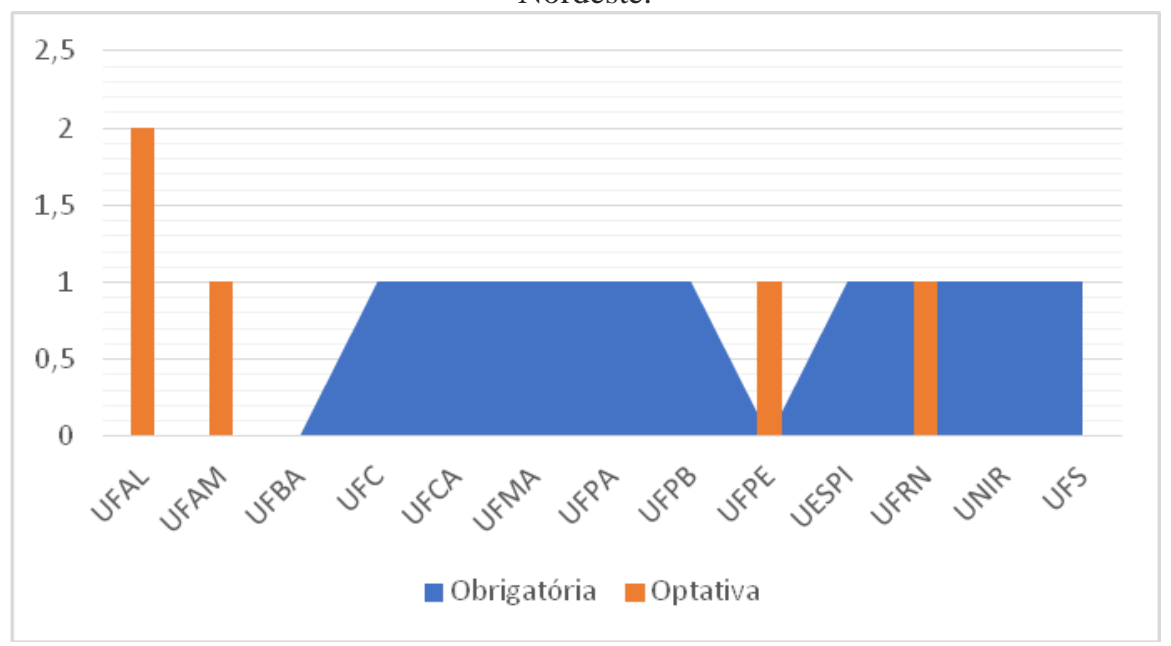

Fonte: Dados da pesquisa (2019).

No Quadro 2, a seguir, listamos as disciplinas que tratam de leitura e autoria e suas ementas. Observamos que praticamente todas têm carga-horária de 60h, a exceção da disciplina Leitura e biblioteca, da UFAM, que tem 45h; da disciplina Teoria e prática de leitura, de 64h, oferecida pela UFC e UFCA; e Leitura e competência informacional, da UFPA, também de 64h. Vale ressaltar que a Universidade Federal do Ceará (UFC) e a Universidade Federal do Cariri (UFCA) têm o mesmo currículo e basicamente o mesmo PPC, alterando somente os dados particulares de cada instituição.

$\mathrm{Na}$ UFAL, tanto a disciplina de Leitura e biblioteca quanto a de Contação de história têm bastante enfoque em biblioteca escolar e literatura infantojuvenil, o que aparece também nas bibliografias de ambas, disponíveis no PPC, que contemplam, por exemplo, autores como Paulo Freire e obras sobre letramento informacional. Do conteúdo da ementa de Leitura e biblioteca, a disciplina parece fornecer para o estudante um bom panorama a respeito da leitura, do leitor e de como trabalhar as práticas de leitura na biblioteca visando à formação de leitores. Podemos, então, inferir que essa disciplina capacite o 
estudante para, quando estiver à frente de uma biblioteca, desempenhe os papéis de mediador de leitura e formador de leitores.

Já em relação à ementa de Contação de história, destacamos: o uso e as possibilidades dessa prática também em ambientes educacionais não formais, o que indica um entendimento do papel formador do bibliotecário, que deve ser capaz de operar diferentes técnicas para incentivar a leitura; e a contação de história com recurso terapêutico, possivelmente introduzindo o estudante nas discussões sobre biblioterapia e preparando-o para atuar nessa área.

No que diz respeito à autoria, entretanto, as ementas de nenhuma das duas disciplinas indicam que essa seja uma temática trabalhada por elas.

Quadro 2 - Ementas das disciplinas sobre leitura e autoria nos cursos de Biblioteconomia.

\begin{tabular}{|c|c|c|c|}
\hline IFES & DISCIPLINA & $\begin{array}{l}\text { TIPO } \\
\text { (CH) }\end{array}$ & EMENTA \\
\hline \multirow[t]{2}{*}{ UFAL } & Leitura e biblioteca & $\begin{array}{l}\text { Optativa } \\
\text { (60h) }\end{array}$ & $\begin{array}{l}\text { Leitura, natureza e funções. Formação } \\
\text { do leitor: motivações, interesse de } \\
\text { leitura. Tipologias do leitor. Literatura } \\
\text { infanto-juvenil. Discussões sobre } \\
\text { gênero e panorama histórico. Literatura } \\
\text { infanto-juvenil e pedagogia. Práticas de } \\
\text { leitura na biblioteca. Pesquisa escolar e } \\
\text { biblioteca. }\end{array}$ \\
\hline & $\begin{array}{l}\text { Contação de } \\
\text { história }\end{array}$ & $\begin{array}{l}\text { Optativa } \\
\text { (60h) }\end{array}$ & $\begin{array}{l}\text { Contação de histórias como forma de } \\
\text { incentivo à leitura: usos e possibilidades } \\
\text { em ambientes educacionais formais e } \\
\text { não formais. A contação de história } \\
\text { como recurso terapêutico. }\end{array}$ \\
\hline UFAM & Leitura e biblioteca & $\begin{array}{l}\text { Optativa } \\
(45 \mathrm{~h})\end{array}$ & $\begin{array}{l}\text { Histórico, conceito e objetivo do código } \\
\text { de escrita e da biblioteca. Leitura } \\
\text { infantil, juvenil e adulta. Valor político, } \\
\text { econômico e social da leitura. }\end{array}$ \\
\hline UFC & $\begin{array}{c}\text { Teoria e prática da } \\
\text { leitura }\end{array}$ & $\begin{array}{l}\text { Obrigatória } \\
(64 \mathrm{~h})\end{array}$ & $\begin{array}{l}\text { Enfoca os processos da leitura e da } \\
\text { escrita sob diferentes concepções, } \\
\text { enfatizando, sobretudo, as } \\
\text { sociointeracionistas, a estética da } \\
\text { recepção e o letramento. Estuda as } \\
\text { políticas de leitura no Brasil para } \\
\text { contribuir na compreensão das atuais } \\
\text { problemáticas da leitura/escrita, do } \\
\text { livro, da biblioteca, da formação do } \\
\text { leitor e das práticas leitoras. }\end{array}$ \\
\hline UFCA & $\begin{array}{c}\text { Teoria e prática da } \\
\text { leitura }\end{array}$ & $\begin{array}{l}\text { Obrigatória } \\
\text { (64h) }\end{array}$ & $\begin{array}{l}\text { Enfoca os processos da leitura e da } \\
\text { escrita sob diferentes concepções, } \\
\text { enfatizando, sobretudo, as } \\
\text { sociointeracionistas, a estética da } \\
\text { recepção e o letramento. Estuda as } \\
\text { políticas de leitura no Brasil para } \\
\text { contribuir na compreensão das atuais }\end{array}$ \\
\hline
\end{tabular}




\begin{tabular}{|c|c|c|c|}
\hline & & & $\begin{array}{l}\text { problemáticas da leitura/escrita, do } \\
\text { livro, da biblioteca, da formação do } \\
\text { leitor e das práticas leitoras. }\end{array}$ \\
\hline UFMA & $\begin{array}{l}\text { Leitura e formação } \\
\text { de leitores }\end{array}$ & $\begin{array}{l}\text { Obrigatória } \\
\quad(60 \mathrm{~h})\end{array}$ & $\begin{array}{l}\text { Concepção de leitura. Processo de } \\
\text { formação de leitores. Práticas de leitura } \\
\text { na família, na escola e na biblioteca. } \\
\text { Política de incentivo à leitura no Brasil. } \\
\text { Literatura infantil e juvenil: origem, } \\
\text { conceito, características, produção } \\
\text { editorial brasileira e difusão. Estratégias } \\
\text { de leitura. Planejamento de atividades } \\
\text { de leitura para crianças e jovens. }\end{array}$ \\
\hline UFPA & $\begin{array}{c}\text { Leitura e } \\
\text { competência } \\
\text { informacional }\end{array}$ & $\begin{array}{l}\text { Obrigatória } \\
\quad(64 \mathrm{~h})\end{array}$ & $\begin{array}{l}\text { História da leitura no mundo ocidental. } \\
\text { Leitura e competência informacional: } \\
\text { questões conceituais. O movimento da } \\
\text { competência informacional. Teorias, } \\
\text { práticas e estratégias de leitura como } \\
\text { aperfeiçoamento pessoal e profissional. } \\
\text { A leitura como um ato político e de } \\
\text { cidadania. Apreensão e produção de } \\
\text { textos técnicos e acadêmicos. Redação } \\
\text { científica: o texto dissertativo. } \\
\text { Relatório/fichamento de leituras. } \\
\text { Métodos de comunicação oral. }\end{array}$ \\
\hline UFPB & $\begin{array}{l}\text { Leitura e produção } \\
\text { de textos }\end{array}$ & $\begin{array}{l}\text { Obrigatória } \\
\quad(60 \mathrm{~h})\end{array}$ & $\begin{array}{l}\text { Concepções de leitura e texto. Gêneros } \\
\text { textuais. Intertextualidade. Estratégias } \\
\text { de leitura. Hipertexto. Estilo. Coesão e } \\
\text { coerência. Produção de textos técnico- } \\
\text { científicos na Ciência da Informação. }\end{array}$ \\
\hline UFPE & Seminários de leitura & $\begin{array}{l}\text { Optativa } \\
(60 \mathrm{~h})\end{array}$ & $\begin{array}{l}\text { Teorias sobre texto e leitura. } \\
\text { Habilidades de compreensão e } \\
\text { interpretação de textos de diferentes } \\
\text { gêneros. Fatores de textualidade. } \\
\text { Estratégias de leitura. Leitura como } \\
\text { atividade interativa de produção de } \\
\text { sentidos. }\end{array}$ \\
\hline UFRN & $\begin{array}{l}\text { Biblioteca escolar e } \\
\text { formação de leitor }\end{array}$ & $\begin{array}{l}\text { Optativa } \\
(60 \mathrm{~h})\end{array}$ & $\begin{array}{c}\text { Biblioteca escolar: funções e } \\
\text { modalidades de atuação na sociedade } \\
\text { brasileira. Políticas públicas de } \\
\text { incentivo à leitura e programas de } \\
\text { formação de leitores. Letramento } \\
\text { informacional. A inserção da biblioteca } \\
\text { escolar no projeto político pedagógico } \\
\text { da escola. O bibliotecário como } \\
\text { mediador cultural. }\end{array}$ \\
\hline & $\begin{array}{l}\text { Prática de leitura e } \\
\text { produção de textos }\end{array}$ & $\begin{array}{l}\text { Obrigatória } \\
\qquad(60 \mathrm{~h})\end{array}$ & $\begin{array}{c}\text { Leitura e produção de textos, com ênfase } \\
\text { na textualidade e tipologia. }\end{array}$ \\
\hline UNIR & $\begin{array}{l}\text { Leitura, escrita e } \\
\text { cultura }\end{array}$ & $\begin{array}{l}\text { Obrigatória } \\
\text { (60h) }\end{array}$ & $\begin{array}{l}\text { Relações teóricas sob o ponto de vista de } \\
\text { aspectos da História, entre as práticas de } \\
\text { leitura e suas diversas manifestações } \\
\text { culturais. As historicidades das práticas } \\
\text { entre: autores, mediadores da leitura e a } \\
\text { constituição dos leitores. }\end{array}$ \\
\hline
\end{tabular}




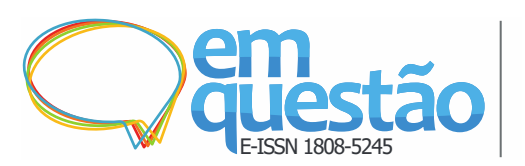

Leitura e autoria sob uma perspectiva dialógica na formação em Biblioteconomia no Brasil

Natália Raposo da Fonsêca, Hélio Márcio Pajeú

\begin{tabular}{|c|c|c|c|}
\hline UFS & $\begin{array}{l}\text { Letramento e } \\
\text { competência } \\
\text { informacional }\end{array}$ & $\begin{array}{c}\text { Obrigatória } \\
\quad(60 \mathrm{~h})\end{array}$ & $\begin{array}{l}\text { Por meio do estudo do letramento e da } \\
\text { formação de competência informacional } \\
\text { como quesito da relação } \\
\text { bibliotecário/usuário, estabelecer a } \\
\text { relação entre o pleno usufruto da } \\
\text { produção material e cultural da } \\
\text { sociedade e o desenvolvimento de } \\
\text { habilidades, competências, hábitos e } \\
\text { gostos no âmbito da leitura. }\end{array}$ \\
\hline
\end{tabular}

Fonte: Dados da pesquisa (2019).

Não tivemos acesso à bibliografia da disciplina Leitura e biblioteca, oferecida pela UFAM, pois esta não consta no PPC. Apesar disso, sua ementa não deixa dúvida de que corresponde à concepção de leitura que buscamos, ao prever o ensino do "valor político, econômico e social da leitura". Mesmo que o leitor desconheça ou ignore o caráter político do ato de ler, isso não faz com que tal ato deixe de sê-lo, não anula esse componente, pois ele faz parte do processo. Ler não é neutro, é político, e não há como desvincular as duas coisas (BRITTO, 1999; FREIRE, 1989). Da mesma forma é a palavra, necessariamente dialógica, ideológica quando convertida em signo (BAKHTIN, 2006).

Já a disciplina Teoria e prática de leitura é ofertada tanto pela UFC quanto pela UFCA. De acordo com seu programa, disponibilizado no PPC, ela se justifica pela deficiência do sistema de ensino brasileiro e pela falta de bibliotecas escolares: “A disciplina vem suprir, não só a lacuna deixada, mas preparar os alunos para desempenhar o papel de mediadores da leitura como também, o de formador de leitores na sociedade" (UNIVERSIDADE FEDERAL DO CEARÁ, 2006, p. 82, grifo nosso).

Destacamos que essa ementa enfatiza o ensino da teoria e a aplicação da prática, bem como prevê a discussão dos processos e problemáticas da leitura e da escrita, denotando um entendimento de que não há leitor sem que haja um autor. Tão importante quanto ensinar estudantes de Biblioteconomia a formar leitores, é ensiná-los a formar autores e a descobrirem-se eles próprios também autores de textos e de mundos possíveis.

A bibliografia inclui, entre outras, discussões sobre produção textual, políticas de leitura e leitura como política, além de incluir a obra Marxismo e filosofia da linguagem, de Mikhail Bakhtin, em quem ancoramos as concepções de leitura e autoria que defendemos. 
Desse modo, ao enfocar também os processos de escrita, entendendo-os como indissociáveis dos de leitura, as disciplinas da UFC e da UFCA podem contribuir para preparar bibliotecários que, ao mediar leitura, tenham em mente a complexidade e a potência dessa atividade, que vai muito além da mera indicação de livro ou da narração de histórias.

Já a ementa da disciplina Leitura e formação de leitores, do curso da UFMA, destaca concepções de leitura; processos de formação de leitores; práticas de leitura em espaços diferentes da escola e da biblioteca; e políticas de incentivo à leitura. Contempla, também, questões relativas à literatura e à leitura voltadas para o público infantil e juvenil. No PPC não estão disponíveis as bibliografias, o que nos permitiria uma análise mais detalhada.

No curso da UFPA, a disciplina Leitura e competência informacional tem como objetivo propiciar conhecimentos sobre teorias e práticas relacionadas ao ato de ler e de escrever; estimular a produção textual entre os estudantes de Biblioteconomia e prepará-los para atuar no incentivo à leitura junto a crianças, jovens e adultos; além de discutir a questão do letramento informacional. $\mathrm{Na}$ ementa, destacamos o tópico "A leitura como um ato político e de cidadania", o que denota uma concepção freiriana de leitura, com a qual concordamos.

Nesse sentido, Targino (2020, p. 12) alerta que

[...] é urgente conscientizar o bibliotecário de que o objeto de sua profissão é a informação e, portanto, deve agir como catalisador e difusor do conhecimento dentro da comunidade, advindo daí seu potencial político como ator e autor de mudanças sociais.

Em relação ao curso da UFPB, o projeto político-pedagógico não disponibiliza a bibliografia da disciplina Leitura e produção de textos, somente a ementa, que embora destaque exclusivamente a produção de textos técnicocientíficos da área de Ciência da Informação, também destaca concepções de leitura, gêneros textuais e intertextualidade, tópicos que implicam pensar os processos de leitura e autoria como essencialmente dialógicos, ainda que isso possa não estar expresso exatamente dessa forma.

Por sua vez, a disciplina Seminários de leitura, do curso de Biblioteconomia da UFPE, destaca em sua ementa o estudo dos gêneros textuais, a importância da compreensão e da interpretação de textos — o que vai 
além da leitura - além dos fatores de textualidade, ou seja, fatores externos ao texto, que influenciam tanto na leitura quanto na escrita. Outro tópico destacado na ementa é a "leitura como atividade interativa de produção de sentidos", o que vai ao encontro da perspectiva bakhtiniana da linguagem.

\begin{abstract}
A busca da compreensão das formas de produção do sentido, da significação, e as diferentes maneiras de surpreender o funcionamento discursivo impeliram Bakhtin na direção de uma estética e de uma ética da linguagem que, mesmo tendo nos estudos a respeito de Rabelais e Dostoiévski um elevado grau de sistematização e, no gênero romance, o ápice da elaboração, não deixaram de examinar também a sistematicidade do discurso cotidiano, contribuindo, portanto, para uma nova perspectiva a respeito da linguagem humana e de seus estudos. (BRAIT, 2005, p. 87)
\end{abstract}

A bibliografia da disciplina inclui títulos que abordam tanto o texto em si quanto o leitor e o autor, além de incluir A importância do ato de ler, obra de Paulo Freire, também encontrada em bibliografias de outras disciplinas aqui analisadas. Embora não haja obras de Bakhtin, é preciso ressaltar que as bibliografias não costumam se manter completamente inalteradas ao longo dos semestres, de modo que é possível haver mais discussões sobre autoria e conceitos bakhtinianos do que sugerem os documentos encontrados.

Na UFRN, a disciplina optativa Biblioteca escolar e formação de leitor, embora trabalhe a questão desse tipo de biblioteca, também se propõe a discutir o papel do bibliotecário como mediador cultural. Levando em conta o contexto da escola e a biblioteca escolar, Lima e Perrotti (2016, p. 175) consideram que “[...] a dimensão pedagógica da mediação cultural caracteriza o mediador cultural também como um educador que atua desenvolvendo relações individuais e públicas e que trabalha com a intersubjetividade, a autonomia e a política”.

A bibliografia da disciplina aponta ainda a existência de discussões acerca de letramento, competência informacional e práticas bibliotecárias na formação do leitor. Nos cursos de todas as outras universidades selecionadas nesta pesquisa encontramos disciplinas sobre biblioteca escolar, entretanto, boa parte delas focava quase exclusivamente na organização do espaço.

A outra disciplina do curso da UFRN, Prática de leitura e produção de texto, destaca em sua ementa a ênfase no estudo da textualidade e da tipologia 
textual. A bibliografia contém diversos títulos sobre discurso e construção de sentidos a partir do texto, indicando que ali o texto não é entendido como algo neutro, o que de fato não é. Vale ressaltar que essa disciplina, obrigatória do curso da UFRN, é oferecida pelo Departamento de Letras, o que pode indicar uma deficiência do quadro de professores do Departamento de Ciência da Informação em relação à leitura "não documentária".

Já a disciplina Leitura, escrita e cultura, do curso de Biblioteconomia da UNIR, trata das relações entre as práticas de leitura e suas manifestações culturais, além da historicidade das práticas entre autores, mediadores de leitura (os bibliotecários) e a constituição dos leitores. Dessa forma, entendendo a leitura como fenômeno discursivo, localizado em um contexto cultural determinado, pois, conforme pontua Bakhtin (2003, p. 389-390), "não pode haver palavra separada do locutor, da situação deste e da sua relação com o ouvinte, separada da situação que os liga [...]".

No que tange à inter-relação entre autores, mediadores e leitores, Targino (2020) afirma que é indispensável reconhecer a relevância da mediação de leitura na formação dos chamados leitores literários, ou seja, aqueles que leem por prazer, como prática cultural, e destaca o papel da leitura para a (trans)formação do leitor em autor: "A leitura criativa pode ser vista, de forma otimista, como o fim do percurso do indivíduo como leitor e o começo de sua caminhada como produtor de textos" (TARGINO, 2020, p. 6).

Por último, o curso da UFS oferece a disciplina Letramento $e$ competência informacional, que destaca a importância do letramento e da competência informacional para que os indivíduos possam efetivamente usufruir dos produtos culturais e informacionais, incluindo a leitura.

Observamos que nenhuma das ementas analisadas, nem mesmo as das disciplinas da UFS e da UFPA, que abordam a questão da competência informacional, mencionam as novas tecnologias de informação e comunicação, que, sem dúvida, impactam os processos de leitura e escrita. A valorização do suporte livro parece continuar tendo destaque na formação acadêmica dos estudantes, contribuindo para formar bibliotecários que encontram dificuldades para pensar e entender a leitura e a autoria para além dos livros. 


\section{Considerações finais}

A partir da análise dos Projetos Pedagógicos dos Cursos de Biblioteconomia do país, com recorte nas regiões Norte e Nordeste, verificamos que praticamente todos os cursos oferecem alguma disciplina sobre leitura e autoria (a exceção é a Universidade Federal da Bahia). Apesar disso, pudemos observar que, mesmo sendo ofertadas, a quantidade de disciplinas é baixa comparada à carga-horária total dos cursos. Isso confirma nossa hipótese de que o ensino da leitura de um ponto de vista mais tecnicista, como a leitura documentária, por exemplo, ainda recebe mais destaque na formação biblioteconômica.

Também vale destacar que, dentre as disciplinas elencadas, poucas se referem diretamente à questão da autoria; e a leitura acaba sendo prioritária e desvinculada da escrita. Os cursos das universidades federais da Paraíba, do Rio Grande do Norte e de Rondônia têm disciplinas que contemplam a escrita já no título: Leitura e produção de textos; Prática de leitura e produção de textos; e Leitura, escrita e cultura - respectivamente. Ainda assim, as ementas não se alongam na questão da escrita, contribuindo para formar bibliotecários mediadores de leitura, formadores de leitores, mas não formadores de autores, não necessariamente autores de literatura, mas de textos — escritos ou não capazes de transformar contextos e realidades daqueles que os produzem.

O curso de Biblioteconomia da UFBA, que não oferece nenhuma disciplina sobre leitura, oferece várias disciplinas obrigatórias de literatura brasileira. Isso também ocorre em cursos de outras universidades analisadas, onde há diversas disciplinas de literatura brasileira, internacional, infantojuvenil etc. Disso depreendemos que a formação do bibliotecário ainda entende a leitura como muito associada à literatura e, necessariamente, à leitura de livros, e não à "leitura de mundo", conforme preconizava Freire (1989).

Por último, a análise das ementas nos mostra a valorização do suporte livro. Por isso, acreditamos que, em relação à leitura — seja literária ou de qualquer outro tipo — , é importante que a Biblioteconomia abrace novos suportes (audiolivros, livros digitais, redes sociais etc.), fazendo da tecnologia 
uma aliada que ajude o bibliotecário a se aproximar dos indivíduos leitores/autores reais e potenciais - , fazendo jus ao potencial transformador da profissão.

Além disso, a mediação cultural e de leitura pode e deve ser adotada em todos os tipos de biblioteca, mas para que de fato sirva a propósitos críticos, democráticos e de inclusão social, é preciso que a formação do bibliotecário como mediador incorpore o elemento social e político ao cotidiano profissional.

\section{Referências}

ABREU, Márcia. Diferentes formas de ler. 2000. Disponível em: http://www.unicamp.br/iel/memoria/Ensaios/Marcia/marcia.htm. Acesso em: 15 fev. 2019.

ALMEIDA JÚNIOR, Oswaldo Francisco. F.; BICHERI, Ana Lúcia Antunes de. O. Bibliotecário escolar: um mediador de leitura. Biblioteca Escolar em Revista, Ribeirão Preto, v. 2, n. 1, p. 41-54, 2013.

ARÁN, Pampa Olga. A questão do autor em Bakhtin. Bakhtiniana, São Paulo, v. 9, n. especial, p. 4-25, jan./jul. 2014.

BAKHTIN, Mikhail. Estética da criação verbal. 4. ed. São Paulo: Martins Fontes, 2003.

BAKHTIN, Mikhail. Estudo das ideologias e filosofia da linguagem. In: BAKHTIN, Mikhail. Marxismo e filosofia da linguagem. São Paulo: Hucitec, 2006.

BAKHTIN, Mikhail. O discurso no romance. In: BAKHTIN, Mikhail. Questões de literatura e de estética: a teoria do romance. São Paulo: Editora da Unesp: Hucitec, 1988.

BAKHTIN, Mikhail. Palavra própria e palavra outra: na sintaxe da enunciação. A palavra na vida e na poesia: introdução ao problema da poética sociológica. São Carlos: Pedro \& João Editores, 2011.

BORTOLIN, Sueli. Mediação oral literária: a voz dos bibliotecários lendo ou narrando. 2010. Tese (Doutorado em Ciência da Informação) - Faculdade de Filosofia e Ciências, Universidade Estadual Paulista 'Júlio de Mesquita Filho', Marília, SP, 2010.

BRAIT, Beth. Bakhtin e a natureza constitutivamente dialógica da linguagem. In: BRAIT, Beth (org.). Bakhtin, dialogismo e construção do sentido. rev. Campinas: Editora da Unicamp, 2005. 
BRITTO, Luiz Percival Leme. Leitura e Política. In: EVANGELISTA, Aracy Alves Martins; BRANDÃO, Heliana Maria B.; MACHADO, Maria Zélia Versiani (org.). A escolarização da leitura literária: o jogo do livro infantil e juvenil. Belo Horizonte: Autêntica, 1999.

BRITTO, Luiz Percival Leme; BARZOTTO, Valdir Heitor. Promoção x mitificação da leitura. Boletim Informativo da Associação de Leitura do Brasil, Campinas, ago. 1998.

CLARK, Katerina; HOLQUIST, Michael. Mikhail Bakhtin. São Paulo: Perspectiva, 1998.

CECCANTINI, João Luís. Mentira que parece verdade: os jovens não leem e não gostam de ler. In: FAILLA, Zoara (org.) Retratos da leitura no Brasil 4. Rio de Janeiro: Sextante, 2016.

FAILLA, Zoara (org.) Retratos da leitura no Brasil 4. Rio de Janeiro: Sextante, 2016.

FARACO, Carlos Alberto. Linguagem \& Diálogo: as ideias linguísticas do Círculo de Bakhtin. São Paulo: Parábola Editorial, 2009.

FREIRE, Paulo. A importância do ato de ler: em três artigos que se completam. São Paulo: Autores Associados, 1989.

FREIRE, Paulo. Pedagogia do oprimido. Rio de Janeiro: Paz e Terra, 1987.

FONSÊCA, Natália Raposo da; GOMES, Isaltina Maria de Azevedo. Dialogismo e vozes discursivas na cobertura de saúde: leituras do Bom Dia Pernambuco. In: CONGRESSO BRASILEIRO DE CIÊNCIAS DA COMUNICAÇÃ̃, 37., Foz do Iguaçu. Anais [...]. São Paulo: Intercom, 2014.

GERALDI, João Wanderley. Ancoragens: estudos bakhtinianos. São Carlos: Pedro \& João Editores, 2010.

LIMA, Celly de Brito; PERROTTI, Edmir. Bibliotecário: um mediador cultural para a apropriação cultural. Informação@Profissões, Londrina, v. 5, n. 2, p. 161-180, jul./dez. 2016.

MIOTELLO, Valdemir. Ideologia. In: BRAIT, Beth (org.). Bakhtin: conceitoschave. São Paulo: Contexto, 2012.

PAJEÚ, Hélio Márcio. Do texto ao gênero do discurso. In: PAJEÚ, Hélio Márcio. Os gêneros do discurso na criação estética colaborativa. São Carlos: Pedro \& João Editores, 2014. 
PAJEÚ, Hélio Márcio. Leitura e autoria sob uma perspectiva dialógica no curso de Biblioteconomia da UFPE: a vivência da disciplina Seminários de Leitura. In: ENCONTRO NACIONAL DE PESQUISA EM CIÊNCIA DA INFORMAÇÃO, 17., 2016, Salvador. Anais [...]. Salvador: PPGCI: UFBA, 2016.

PAJEÚ, Hélio Márcio; ALMEIDA, Arthur Henrique Feijó de. A mediação cultural na biblioteca escolar e o bibliotecário infoeducador. Revista Digital de Biblioteconomia \& Ciência da Informação, Campinas, v. 18, 2020.

SOBRAL, Adail Ubirajara. A concepção de autor do "Círculo Bakhtin, Medvedev, Voloshinov": confrontos e definições. Macabéa - Revista Eletrônica do Netlli, Crato, v. 1, n. 2, p. 123-142, dez. 2012.

SOUSA, Laiana Ferreira de; FEITOZA, Rayan Aramís de Brito. Responsabilidade social do bibliotecário enquanto mediador literário: análise nos currículos dos cursos de graduação em biblioteconomia no nordeste do Brasil. Informação@Profissões, Londrina, v. 7, n. 1, p. 58-76, 2018.

SOUZA, Solange Jobim e. Mikhail Bakhtin e Walter Benjamin: polifonia, alegoria e o conceito de verdade no discurso da ciência contemporânea. In: BRAIT, Beth (org.). Bakhtin, dialogismo e construção do sentido. Campinas: Editora da Unicamp, 2005.

TARGINO, Maria das Graças. Mediação cultural e mediação da leitura como estratégia de inclusão social: bibliotecas comunitárias. Revista Brasileira de Biblioteconomia e Documentação, São Paulo, v. 16, p. 1-17, 2020.

UNIVERSIDADE FEDERAL DO CEARÁ. Pró-Reitoria de Graduação. Projeto Pedagógico do Curso de Biblioteconomia. Fortaleza: UFC, 2006.

VÁ LER UM LIVRO. Como ler mais e melhor? 6 técnicas para ler mais livros. [S. l.: s. $n$ ], 2019. 1 vídeo (8 min). Publicado pelo canal Vá ler um livro.

VERGARA, Sylvia Constant. Projetos e relatórios de pesquisa em administração. São Paulo: Atlas, 2003.

\section{Reading and authorship from a dialogical perspective in training in Library Science in Brazil}

\footnotetext{
Abstract: Reading has a very direct relationship with the performance of the librarian, at the same time that discussions about it do not occupy a prominent
} 
place in library science curriculum. What is observed is a highlight for technical reading, such as documentary reading. In this sense, the objective of this research is to verify which place the reading and authorship issues occupy in the Library Science courses in Brazil - with the North and Northeast regions as an outline - and under which theoretical perspectives have been developed in the formation of future librarians. From a Bakhtinian dialogical view, reading is discussed as a political, social, ideological and responsible act, understanding the role of the librarian as a mediator of culture and information. This study is characterized as qualitative, exploratory, descriptive and documentary research. It analyzes the Pedagogical Projects of the Librarianship Courses of 13 federal universities in the North and Northeast of Brazil, focusing on the disciplines that deal with reading and authorship under a dialogical bias. Of these, discipline program and, in some cases, bibliographies were also analyzed. The results show that the majority of the analyzed Librarianship courses offer some discipline on reading and authorship, however it is still an inexpressive offer compared to the number of "technical" subjects. There was also a tendency to think about reading linked to literature, books, children, young people and school library. In addition, it was observed that the debate on authorship receives little prominence, being directly mentioned in a few analyzed discipline programs.

Keywords: Reading. Authorship. Library Science. Dialogism.

Recebido: $23 / 06 / 2020$

Aceito: 01/12/2020

\section{Declaração de autoria}

Concepção e elaboração do estudo: Natália Raposo da Fonsêca, Hélio Márcio Pajeú

Coleta de dados: Natália Raposo da Fonsêca

Análise e interpretação dos dados: Natália Raposo da Fonsêca, Hélio Márcio Pajeú

Redação: Natália Raposo da Fonsêca, Hélio Márcio Pajeú

Revisão crítica do manuscrito: Hélio Márcio Pajeú

\section{Como citar}

FONSÊCA, Natália Raposo da; PAJEÚ, Hélio Márcio. Leitura e autoria sob uma perspectiva dialógica na formação em Biblioteconomia no Brasil. Em Questão, Porto Alegre, v. 27, n. 4, p. 328-358, 2021 .Doi: http://dx.doi.org/10.19132/1808-5245274.328-358 
Leitura e autoria sob uma perspectiva dialógica na

formação em Biblioteconomia no Brasil

Natália Raposo da Fonsêca, Hélio Márcio Pajeú

${ }^{1}$ Os cursos da Universidade Federal da Bahia (UFBA) e da Universidade Federal de Sergipe (UFS) denominam-se Biblioteconomia e Documentação.

${ }^{2}$ A exceção é a Universidade Estadual do Piauí (UESPI), que é uma instituição da esfera estadual. 